\title{
Physiological Sleep Propensity Might Be Unaffected by Significant Variations in Self-Reported Well-Being, Activity, and Mood
}

\author{
Arcady A. Putilov \\ Research Institute for Molecular Biology and Biophysics, 2 Timakova Street, Novosibirsk 630117, Russia \\ Correspondence should be addressed to Arcady A. Putilov; putilov@ngs.ru
}

Received 21 May 2015; Revised 21 July 2015; Accepted 22 July 2015

Academic Editor: Liborio Parrino

Copyright (C) 2015 Arcady A. Putilov. This is an open access article distributed under the Creative Commons Attribution License, which permits unrestricted use, distribution, and reproduction in any medium, provided the original work is properly cited.

Background and Objective. Depressive state is often associated with such physical symptoms as general weakness, fatigue, tiredness, slowness, reduced activity, low energy, and sleepiness. The involvement of the sleep-wake regulating mechanisms has been proposed as one of the plausible explanations of this association. Both physical depressive symptoms and increased physiological sleep propensity can result from disordered and insufficient sleep. In order to avoid the influence of disordered and insufficient sleep, daytime and nighttime sleepiness were tested in winter depression characterized by normal night sleep duration and architecture. Materials and Methods. A total sample consisted of 6 healthy controls and 9 patients suffered from depression in the previous winter season. Sleep latency was determined across 5 daytime and 4 nighttime 20-min attempts to nap in summer as well as in winter before and after a week of 2-hour evening treatment with bright light. Results and Conclusions. Patients self-reported abnormally lowered well-being, activity, and mood only in winter before the treatment. Physiological sleep propensity was neither abnormal nor linked to significant changes in well-being, activity, and mood following the treatment and change in season. It seems unlikely that the mechanisms regulating the sleep-wake cycle contributed to the development of the physical depressive symptoms.

\section{Introduction}

Depression is often associated with such subjective physical complaints as general weakness, fatigue, tiredness, slowness, reduced activity, low energy, and sleepiness [1]. Epidemiological and clinical studies have pointed out that this association might be very strong [2-9], rather complex and bidirectional [10]. Its biological basis has not been fully established [11]. Among several plausible explanations, the involvement of the sleep-wake regulating mechanisms has been proposed [12-14]. However, objective evidence has not been yet provided to support the view that depression is associated with abnormal (e.g., either increased or decreased) physiological sleep propensity. At least, one can draw this conclusion from the results of several independent studies [15-18] applying objective tools of direct measurement of the levels of daytime and nighttime sleepiness, such as the Multiple Sleep Latency Test (MSLT).

Both the physical depressive complaints and increased physiological sleep propensity can result from disordered and insufficient sleep. The contribution of the disordered and insufficient sleep can be avoided in the study of those mildly or moderately depressed conditions that are not obligatorily associated with disruption of nighttime sleep and hyposomnia. Such a study can shed light on the involvement of sleep-wake regulating mechanisms in the development and remission of depressive state. One of such conditions is winter depression or seasonal affective disorder of winter type. Frequent occurrence of hypersomnia and hyperphagia was stressed in its initial description [19]. Moreover, our earlier published polysomnographic research of night sleep in winter depression revealed neither its abnormality in terms of duration and architecture nor its significant effects of the change in season and treatment with bright light on the vast majority of objective characteristics of night sleep [20].

However, it is unknown whether physiological sleep propensity also remains unaffected in this condition. Therefore, the major aims of this report were (i) to test objectively the levels of daytime and nighttime sleepiness in winter 
depression during remission and depressed episode and (ii) to examine strength of relationship of objectively measured sleepiness with lowered well-being, activity, and mood in depressed condition.

\section{Materials and Methods}

The experimental protocol was approved by the Ethics Committee of the Siberian Branch of the Russian Academy of Medical Sciences. All 15 study participants gave written informed consent. The participants were unmedicated, in good general health, and free of any sleep disorders and were not engaged in shift work or long distance travel in the previous 2 months. Controls were also free from any types of mood and psychosomatic disorders. The criteria of Rosenthal et al. [19] were applied for the diagnosis of winter depression. They, however, were more stringent in that a history of complete summer remission was required (see [21, 22] for details). A total sample included 9 women with winter depression. Their depressive episode was clinically diagnosed during the previous study conducted in the winter season. The ages of patients (mean \pm SD) were $34.2 \pm 13.0$ (range from 17 to 56 years old). The ages of 6 women from the control group were in the range from 22 to 55 ( $40.5 \pm 9.7$ years old).

Six women from each group were first studied in summer. Then, five women from each group were restudied in winter, and the patient group was enlarged by adding 3 depressed women with winter depression. Of these 13 participants of the winter study, 7 patients and 4 controls were restudied after a week of 2-hour evening treatment with bright light (2500 lux at the eyes' level). The study was terminated at this stage because the preliminary analysis of its results revealed neither abnormality in the levels of sleepiness in the patient group nor indication of relationship of objectively measured sleepiness with lowered well-being, activity, and mood in depressed condition.

Current clinical symptoms were rated with the 21item Hamilton Rating Scale for Depression (HRSD) [23]. Additionally, the depressive symptoms were self-rated with the 29-item Structured Interview Guide for the Hamilton Depression Rating Scale: Seasonal Affective Disorder (SIGH). The SIGH includes the HRSD and 8-item Addendum concerning atypical depressive symptoms, such as hypersomnia, carbohydrate craving, increased appetite, increased eating, weight gain, fatigue, type B (inversed) diurnal variation, and social withdrawal [24].

After an adaptation night, polysomnographic records were obtained during normally scheduled night sleep (23:008:00) and, thereafter, during 920 -min sleep latency tests in daytime $(10: 00,12: 00,14: 00,16: 00$, and 18:00) and nighttime $(23: 00,1: 00,3: 00$, and 5:00). In the course of any of these recordings the participants were lying in bed in the darkened room of the sleep laboratory and were asked to try to fall asleep and sleep until hearing the awakening signal from the nursing staff.

In order to self-assess subjective state before and after baseline night sleep and before each of 9 20-min sleep attempts, the participants filled the 30-item WAM-Test consisting of 3 10-item subscales named "well-being," "activity," and "mood" [25]. Each subscale includes 10 word pairs with a 7-point response scale printed between each pair of words. The following words exemplify these 3 subscales:

Well-Being

$\begin{array}{lll}\text { 1. Good health } & 3210123 & \text { Bad health } \\ \text { 2. Feel strong } & 3210123 & \text { Feel weak } \\ \text { 7. Able to work } & 3210123 & \text { Broken }\end{array}$

Activity

$\begin{array}{lcc}\text { 3. Passive } & 3210123 & \text { Active } \\ \text { 4. Sedentary } & 3210123 & \text { Agile } \\ \text { 9. Sluggish } & 3210123 & \text { Quick }\end{array}$

Mood

$\begin{array}{lll}\text { 5. Gleeful } & 3210123 & \text { Sad } \\ \text { 6. Good mood } & 3210123 & \text { Bad mood } \\ \text { 11. Happy } & 3210123 & \text { Fortuneless }\end{array}$

After transforming each of the response scales " 3210123 ” into "1234567" or "7654321," a summing score for a subscale varies between 10 and 70. Low, middle, and high levels of subjective state can be distinguished by assigning scores to the intervals $<30,30-50$, and $>50$, respectively [25].

Polysomnographic data were collected via an 8-channel Medicor polygraph (EEG8S, Micromed, Hungary). The sleep recordings were performed using a standard monitoring montage including five EEG channels, two electrooculogram channels, and one chin electromyogram channel. The reported data were mostly taken from $\mathrm{Cz}$-A1 derivation of the International Ten-Twenty System of Electrode Placement (i.e., vertex of the head versus left mastoid). To fix the electrodes, Ten 20 conductive paste was used (Nicolet Biomedical, Madison, Wisconsin, USA). Sleep stages were visually scored by two independent judges. The epochs with discrepant scores were reexamined by both judges together to produce consensus scores. Each epoch of the polysomnographic record was categorized in accord with the standard criteria $[26,27]$ as wake, stage 1 , stage 2 , and stages 3 and 4 (slow wave sleep) of non-REM sleep, REM sleep, or movement.

All statistical analyses were performed with the Statistical Package for the Social Sciences (SPSS) ver. 20.0 (IBM, Armonk, NY, USA). Student's $t$-test was applied to evaluate the differences between patient and control groups on subjective state ratings (Table 1) and on objective evaluations of baseline night sleep and napping attempts (Table 2). Additionally, the effects of treatment on repeated self-ratings and repeated objective measures were tested separately on daytime and nighttime intervals with 3-way repeated measure ANOVAs (rANOVAs). The within-subjects factors were "Time of day" (from 10:00 to 18:00 for the experimental day, and from 23:00 to 5:00 for the baseline and experimental nights) and "Condition" (before versus 
TABLE 1: Results of $t$-test aimed at comparison of assessments of subjective state.

\begin{tabular}{|c|c|c|c|c|c|c|}
\hline \multirow{3}{*}{$\begin{array}{l}\text { Season } \\
\text { Condition } \\
\text { Group }\end{array}$} & \multicolumn{4}{|c|}{ Winter either before or after treatment } & \multirow{2}{*}{\multicolumn{2}{|c|}{$\begin{array}{l}\text { Summer } \\
\text { Remission }\end{array}$}} \\
\hline & \multicolumn{2}{|c|}{ Before } & \multicolumn{2}{|c|}{ After } & & \\
\hline & Patients & Controls & Patients & Controls & Patients & Controls \\
\hline \multicolumn{7}{|c|}{ Daytime WAM (well-being-activity-mood) scorings } \\
\hline 30 -item averaged & $36.6 \pm 10.3^{* *}$ & $54.3 \pm 6.4$ & $51.4 \pm 5.8$ & $56.9 \pm 5.8$ & $47.2 \pm 10.2$ & $53.6 \pm 8.5$ \\
\hline 10-item well-being & $37.8 \pm 11.5^{* *}$ & $57.2 \pm 5.4$ & $52.5 \pm 5.4$ & $59.4 \pm 5.4$ & $48.2 \pm 12.1$ & $55.7 \pm 9.1$ \\
\hline 10-item activity & $32.0 \pm 10.2^{* *}$ & $52.2 \pm 8.4$ & $48.3 \pm 6.2^{*}$ & $57.8 \pm 4.9$ & $42.3 \pm 11.0$ & $51.7 \pm 9.1$ \\
\hline 10-item mood & $39.9 \pm 9.9^{*}$ & $53.4 \pm 6.1$ & $53.4 \pm 6.7$ & $53.5 \pm 8.6$ & $51.1 \pm 6.9$ & $53.6 \pm 9.6$ \\
\hline \multicolumn{7}{|c|}{ Nighttime WAM scorings } \\
\hline 30-item averaged & $33.3 \pm 8.5^{*}$ & $46.5 \pm 7.3$ & $37.0 \pm 7.2^{*}$ & $48.8 \pm 8.1$ & $43.3 \pm 6.7$ & $43.6 \pm 10.2$ \\
\hline 10-item well-being & $32.4 \pm 8.8^{*}$ & $46.1 \pm 11.1$ & $34.2 \pm 6.6^{*}$ & $48.4 \pm 11.6$ & $44.2 \pm 8.3$ & $46.1 \pm 11.3$ \\
\hline 10-item activity & $29.3 \pm 8.7^{*}$ & $42.4 \pm 9.2$ & $33.1 \pm 6.9^{*}$ & $46.4 \pm 6.7$ & $42.9 \pm 6.2$ & $42.4 \pm 10.3$ \\
\hline 10 -item mood & $38.3 \pm 8.9^{*}$ & $50.9 \pm 5.6$ & $43.7 \pm 10.1$ & $51.6 \pm 6.9$ & $42.9 \pm 6.2$ & $42.4 \pm 10.3$ \\
\hline \multicolumn{7}{|c|}{ Depression scorings } \\
\hline 21-item HRSD & $16.2 \pm 4.7^{* * *}$ & $2.6 \pm 3.8$ & $6.7 \pm 2.4^{*}$ & $3.0 \pm 1.2$ & $7.8 \pm 7.1$ & $2.3 \pm 3.2$ \\
\hline 29-item SIGH & $30.9 \pm 8.1^{* * *}$ & $5.6 \pm 8.2$ & $10.0 \pm 3.7^{* *}$ & $3.5 \pm 1.9$ & $11.8 \pm 9.7$ & $3.3 \pm 3.9$ \\
\hline 8-item Addendum & $12.9 \pm 3.5^{* * *}$ & $1.0 \pm 1.2$ & $3.1 \pm 1.5^{* *}$ & $0.0 \pm 0.0$ & $4.0 \pm 2.9$ & $1.0 \pm 0.8$ \\
\hline
\end{tabular}

Notes. WAM: self-scoring on the 30-item WAM Test obtained by averaging over scores provided in daytime and nighttime hours (10:00, 12:00, 14:00, 16:00, and 18:00 and 23:00, 1:00,3:00, and 5:00, resp.); averaged: mean score obtained by further averaging over 3 10-item self-scorings. HRSD: depression score rated with the 21-item Hamilton Rating Scale for Depression; SIGH: self-scoring on the 29-item Structured Interview Guide for the Hamilton Depression Rating Scale: Seasonal Affective Disorder; Addendum: self-scoring on the Addendum items concerning atypical depressive symptoms (see Materials and Methods). Level of significance for difference between the patient and control groups: ${ }^{* * *}(p<0.001),{ }^{* *}(p<0.01)$, and ${ }^{*}(p<0.05)$.

TABLE 2: Results of $t$-test aimed on comparison of objective measures of sleepiness and sleep.

\begin{tabular}{|c|c|c|c|c|c|c|}
\hline \multirow{3}{*}{$\begin{array}{l}\text { Season } \\
\text { Condition } \\
\text { Group }\end{array}$} & \multicolumn{4}{|c|}{ Winter either before or after treatment } & \multirow{2}{*}{\multicolumn{2}{|c|}{$\begin{array}{l}\text { Summer } \\
\text { Remission }\end{array}$}} \\
\hline & \multicolumn{2}{|c|}{ Before } & \multicolumn{2}{|c|}{ After } & & \\
\hline & Patients & Controls & Patients & Controls & Patients & Controls \\
\hline \multicolumn{7}{|c|}{ Latency to stage 1 sleep (SL), min, on 20-min interval of napping attempt and baseline sleep } \\
\hline Daytime & $17.4 \pm 3.9$ & $13.9 \pm 5.3$ & $15.3 \pm 4.2$ & $14.9 \pm 4.8$ & $14.1 \pm 2.6$ & $13.4 \pm 4.7$ \\
\hline Nighttime & $14.2 \pm 5.5$ & $11.5 \pm 4.0$ & $13.4 \pm 4.9$ & $11.7 \pm 4.0$ & $12.6 \pm 4.1$ & $10.1 \pm 5.4$ \\
\hline Baseline & $12.4 \pm 7.7$ & $9.4 \pm 6.7$ & $13.9 \pm 6.0$ & $6.3 \pm 4.7$ & $6.0 \pm 5.9$ & $2.8 \pm 3.2$ \\
\hline \multicolumn{7}{|c|}{ Baseline sleep } \\
\hline TST, min & $483.5 \pm 50.3^{*}$ & $401.8 \pm 68.0$ & $469.9 \pm 37.7$ & $437.0 \pm 36.5$ & $478.8 \pm 42.3^{*}$ & $423.7 \pm 47.6$ \\
\hline SL, min & $21.0 \pm 23.3$ & $9.4 \pm 6.7$ & $23.0 \pm 17.5^{*}$ & $6.3 \pm 4.7$ & $19.2 \pm 17.4$ & $12.0 \pm 6.0$ \\
\hline Wake, min & $14.3 \pm 5.4$ & $21.6 \pm 10.8$ & $11.0 \pm 6.6$ & $8.5 \pm 6.5$ & $11.3 \pm 2.9$ & $36.2 \pm 25.5$ \\
\hline Stage $1, \%$ & $5.2 \pm 1.4$ & $7.2 \pm 2.6$ & $5.9 \pm 1.6^{*}$ & $3.6 \pm 1.4$ & $7.5 \pm 3.8$ & $5.8 \pm 1.2$ \\
\hline Stage 2, \% & $64.9 \pm 6.0$ & $60.9 \pm 6.7$ & $57.7 \pm 6.1$ & $64.5 \pm 2.4$ & $56.9 \pm 9.5$ & $59.9 \pm 9.1$ \\
\hline SWS, \% & $9.7 \pm 4.9$ & $14.8 \pm 4.4$ & $12.8 \pm 4.4$ & $12.6 \pm 3.5$ & $13.9 \pm 9.8$ & $15.1 \pm 9.8$ \\
\hline REM, \% & $20.2 \pm 3.7$ & $17.1 \pm 3.8$ & $23.6 \pm 3.2^{*}$ & $19.3 \pm 2.4$ & $21.7 \pm 2.8$ & $19.2 \pm 4.9$ \\
\hline SE, $\%$ & $92.9 \pm 5.5$ & $92.5 \pm 3.9$ & $93.2 \pm 3.1$ & $96.7 \pm 1.9$ & $95.5 \pm 2.1^{*}$ & $89.7 \pm 5.2$ \\
\hline
\end{tabular}

Notes. SL: Latency to onset of stage 1 sleep; Daytime: mean SL for 5 naps scheduled at 10:00, 12:00, 14:00, 16:00, and 18:00; Nighttime: mean SL for 4 naps at 23:00, 1:00, 3:00, and 5:00; Baseline: SL on the first 20-min interval of Baseline night sleep (light off at 23:00). See also Figure 1. Wake: wake time after sleep onset; sleep stages are given as percentage to Total Sleep Time (TST); SWS: slow wave sleep (stages 3 and 4 sleep); REM: Rapid Eye Movement sleep; SE: sleep efficiency expressed as percentage of sleep time in total bed time (i.e., TST plus total wake time). Level of significance for difference between patients and controls: ${ }^{*}(p<0.05)$.

after the bright light treatment). The between-subjects factor was "Group" (patients versus controls). To control for the type 1 error associated with violation of the assumption of sphericity, all $p$ values were based on Huynh-Feldt's correction of the degrees of freedom, but the original degrees of freedom are reported in the text. Prior to applying these analyses, normality of distribution was tested for each variable by means of the exploratory analysis. The hypothesis of normality (Kolmogorov-Smirnov Z-criterion) was always supported $(p>0.05)$. 


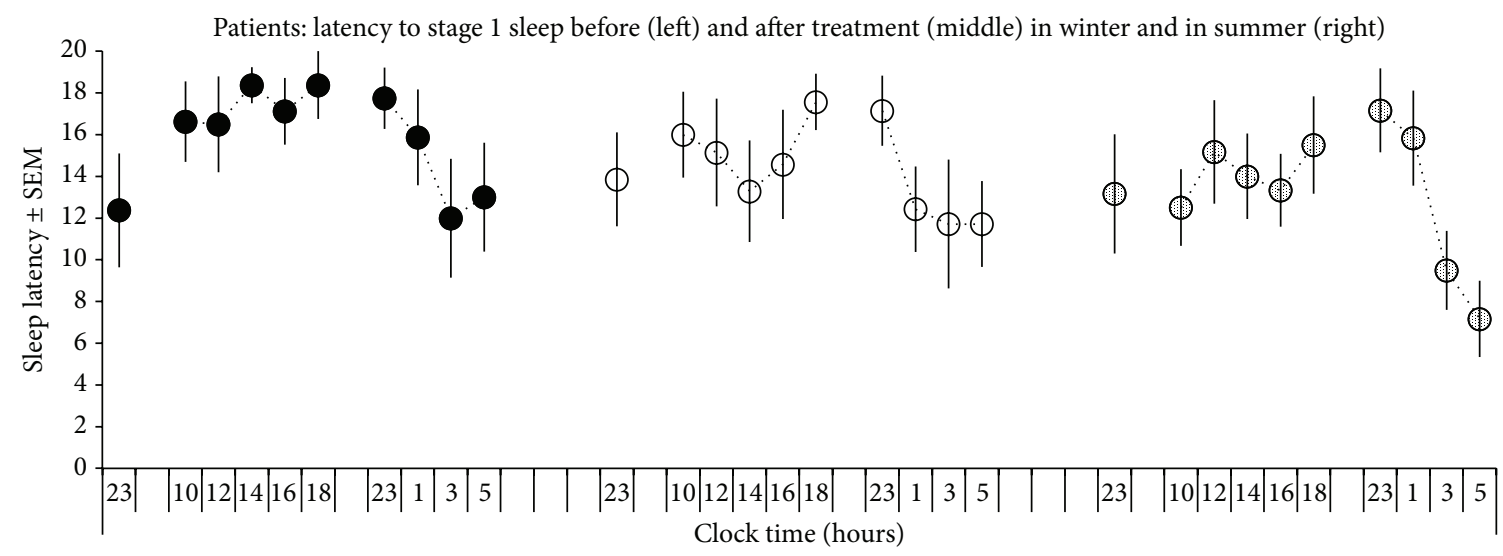

(a)

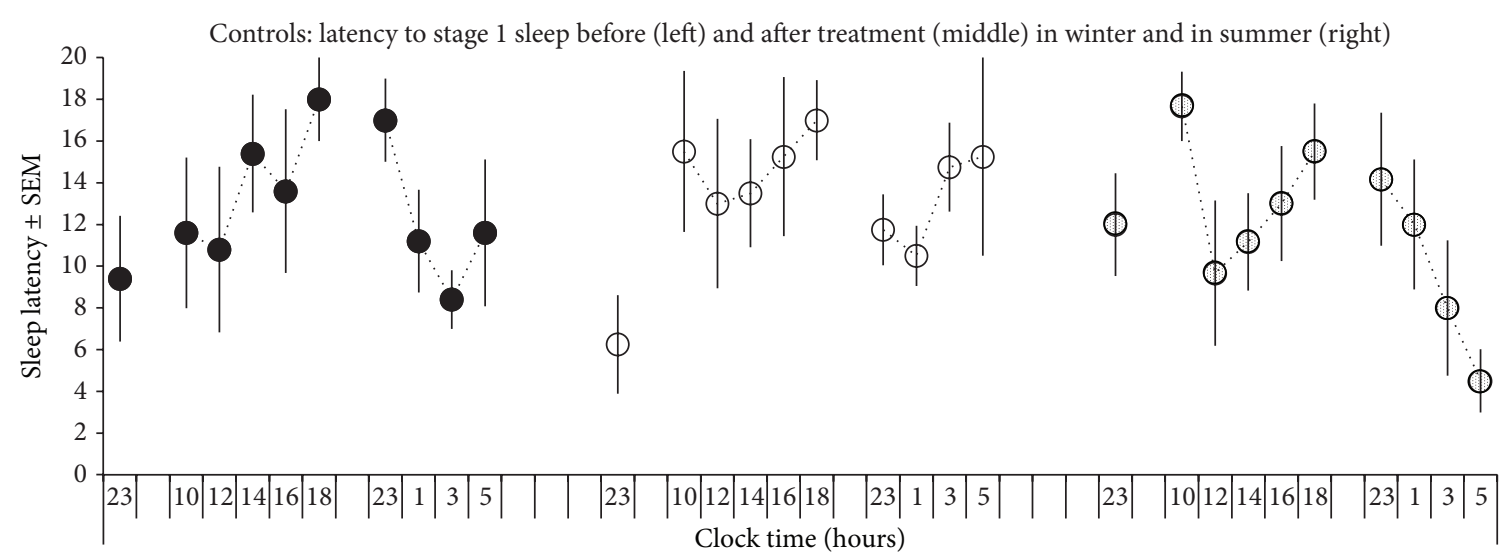

(b)

FIGURE 1: Time course of sleep latency in patients and controls. Sleep latency was tested 10 times on three occasions (in summer and in winter before and after treatment), during the first $20 \mathrm{~min}$ of baseline night sleep and during 5 daytime and 4 nighttime 20-min attempts to nap. See also notes to Table 1 and the results of comparison of patient and control groups in Table 2.

\section{Results}

The self-reported daytime scores on the subscales of wellbeing, activity, and mood were high in the study participants from the control group at any of the three occasions. As expected, the participants form the patient group providing either high or almost high self-scorings of well-being, activity, and mood in summer and in winter after the treatment. In contrast, they were found to be either low or somewhere on the border between low and middle scores in the winter season before the treatment (Table 1). The significant differences between the groups and conditions persisted in the nighttime hours, and, as expected, each score was found to be lowered at night as compared to the corresponding score for daytime hours (Table 1).

Such pattern of the differences between the groups on self-scorings of well-being, activity, and mood was confirmed by rANOVAs. For instance, the analysis of daytime scores obtained by averaging over 3 subscales yielded significant main effect of the factor "Group" as well as significant interaction between this factor and factor "Condition": $F(N=11$, df $=1)=10.4, p=0.010$ and $F(N=11, \mathrm{df}=1)=6.0, p=0.037$, respectively. This interaction indicated dramatic increase of score in the patient group in response to the treatment (see the first line in Table 1).

The opposite pattern of interaction between factors "Group" and "Condition" was revealed by rANOVA of daytime sleep latency: $F(N=11$, df $=1)=5.6, p=0.043$. As can be seen in Figure 1, sleep latency showed a tendency to decrease in patients and increase in controls due to the treatment. Unlike subjective scorings, sleep latency in winter before the treatment was not lowered in patients and did not show significant difference from that of controls (Table 2).

Moreover, the absence of significant changes in sleep latency was confirmed by comparison of mean latencies that were obtained for each participant by averaging over 10 sleep attempts. For instance, none of patients showed lowered mean sleep latency in winter before treatment as compared to that in summer season or in winter after the treatment.

Finally, architecture of baseline night sleep in patients did not differ much from architecture observed in the control group. Instead, participants from the patient group slept even longer than controls in both seasons (Table 2). 


\section{Discussion}

The biological basis of the association of mood disorders with such physical symptoms as general weakness, fatigue, tiredness, slowness, reduced activity, low energy, and sleepiness is poorly understood. Particularly, it remains unknown whether the chronophysiological mechanisms, such as the sleep-wake regulating processes, can contribute to the development of depression and to a beneficial response to an antidepressant treatment. The present study results failed to provide evidence for such contribution. They indicate that the physiological sleep propensity in the patient group was normal and its changes were unrelated to changes in the subjectively reported well-being, activity, and mood. These results imply that wintertime self-scorings of well-being, activity, and mood can be lowered in depressed individuals despite the absence of any significant differences between them and healthy people in objectively measured sleep latency.

However, the limitations of the present analysis include small sample sizes and the absence of severe depressed participants in the patients group. Future studies lacking these limitations might provide a deeper insight into the relationship between depressed mood and sleep-promoting processes.

The treatment and summer conditions were associated with normalization of self-scoring in the patient group. This result is in line with the findings of our earlier studies of sleep-wake patterns in bigger samples of patients with winter depression and healthy controls. In one of these studies $[20,28,29]$ we similarly found that patients self-scored lower than controls their levels of well-being, activity, and mood in winter before light treatment in the morning and afternoon hours, but not after such a treatment. Moreover, the scores were found to be high and identical to those reported by the controls during retesting of subsamples of the participants of winter study in the following summer season. In another experimental investigation $[30,31]$, we demonstrated significant differences between patients and controls on wintertime levels of sleepiness self-assessed with the Karolinska Sleepiness Scale (KSS) and levels of energy self-reported with a visual analog scale.

It is likely that such strong association of health status with activity and sleepiness levels is a very general feature of introindividual variation in subjective states. At least, this association was reported not only for unhealthy but also for practically healthy individuals. For instance, our results resemble the findings reported by Åkerstedt et al. [32]. These findings suggested that worsening of self-perceived health status was the strongest predictor of the increase in KSS selfscorings, whereas the markers of disturbed sleep, such as shorter preceding sleep duration, earlier time of rising, and lower-rated sleep quality, were among less strong albeit yet significant predictors.

\section{Conclusions}

Physiological sleep propensity was neither abnormal in wintertime as compared to summertime nor linked to the changes in well-being, activity, and mood in winter depression with normal sleep architecture and duration. Therefore, it seems unlikely that the mechanisms regulating the sleepwake cycle can contribute to the development of the physical complaints of reduced activity and sleepiness in mildly or moderately depressed patients.

\section{Conflict of Interests}

The author declares that there is no conflict of interests regarding the publication of this paper.

\section{Acknowledgments}

This study was supported by the Russian Foundation for Basic Research (Grants 07-06-00263-a, 10-06-00114-a, and 13-06-00042-a) and the Russian Foundation for Humanities (Grants 06-06-00375-a, 12-06-18001-e, and 15-06-10403-a). The author is indebted to Dr. Konstantin Danilenko, Dr. Vladislav Palchikov, Andrey Abelev, Valery Kozaruk, and Andrey Samsonov for their valuable help in collection of the experimental data set.

\section{References}

[1] L. M. Arnold, "Understanding fatigue in major depressive disorder and other medical disorders," Psychosomatics, vol. 49, no. 3, pp. 185-190, 2008.

[2] L. Christensen and K. Duncan, "Distinguishing depressed from nondepressed individuals using energy and psychosocial variables," Journal of Consulting and Clinical Psychology, vol. 63, no. 3, pp. 495-498, 1995.

[3] C. Hublin, J. Kaprio, M. Partinen, K. Heikkilä, and M. Koskenvuo, "Daytime sleepiness in an adult, Finnish population," Journal of Internal Medicine, vol. 239, no. 5, pp. 417-423, 1996.

[4] A. Tylee, M. Gastpar, J.-P. Lépine, and J. Mendlewicz, "DEPRES II (Depression Research in European Society II): a patient survey of the symptoms, disability and current management of depression in the community," International Clinical Psychopharmacology, vol. 14, no. 3, pp. 139-151, 1999.

[5] M. Fava, "Symptoms of fatigue and cognitive/executive dysfunction in major depressive disorder before and after antidepressant treatment," Journal of Clinical Psychiatry, vol. 64, supplement 14, pp. 30-34, 2003.

[6] M. Fava, "Daytime sleepiness and insomnia as correlates of depression," Journal of Clinical Psychiatry, vol. 65, no. 16, pp. 2732, 2004.

[7] E. O. Bixler, A. N. Vgontzas, H.-M. Lin, S. L. Calhoun, A. Vela-Bueno, and A. Kales, "Excessive daytime sleepiness in a general population sample: the role of sleep apnea, age, obesity, diabetes, and depression," Journal of Clinical Endocrinology and Metabolism, vol. 90, no. 8, pp. 4510-4515, 2005.

[8] S. L. Chellappa and J. F. Araújo, "Excessive daytime sleepiness in patients with depressive disorder," Revista Brasileira de Psiquiatria, vol. 28, no. 2, pp. 126-129, 2006.

[9] G. Hasler, D. J. Buysse, A. Gamma et al., "Excessive daytime sleepiness in young adults: a 20 -year prospective community study," The Journal of Clinical Psychiatry, vol. 66, no. 4, pp. 521529, 2005.

[10] Y. Dauvilliers, R. Lopez, M. Ohayon, and S. Bayard, "Hypersomnia and depressive symptoms: methodological and clinical aspects," BMC Medicine, vol. 11, article 78, 2013. 
[11] K. Demyttenaere, J. De Fruyt, and S. M. Stahl, "The many faces of fatigue in major depressive disorder," International Journal of Neuropsychopharmacology, vol. 8, no. 1, pp. 93-105, 2005.

[12] J. Adrien, "Neurobiological bases for the relation between sleep and depression," Sleep Medicine Reviews, vol. 6, no. 5, pp. 341351, 2002.

[13] D. J. Nutt, S. Wilson, and L. Paterson, "Sleep disorders as core symptoms of depression," Dialogues in Clinical Neuroscience, vol. 10, no. 3, pp. 329-336, 2008.

[14] A. Wirz-Justice, "Biological rhythm disturbances in mood disorders," International Clinical Psychopharmacology, vol. 21, no. 1, pp. S11-S15, 2006.

[15] E. A. Nofzinger, M. E. Thase, C. F. Reynolds III et al., "Hypersomnia in bipolar depression: a comparison with narcolepsy using the multiple sleep latency test," The American Journal of Psychiatry, vol. 148, no. 9, pp. 1177-1181, 1991.

[16] M. Billiard, M. Partinen, T. Roth, and C. Shapiro, "Sleep and psychiatric disorders," Journal of Psychosomatic Research, vol. 38, no. 1, pp. 1-2, 1994.

[17] A. N. Vgontzas, E. O. Bixler, A. Kales, C. Criley, and A. VelaBueno, "Differences in nocturnal and daytime sleep between primary and psychiatric hypersomnia: diagnostic and treatment implications," Psychosomatic Medicine, vol. 62, no. 2, pp. 220-226, 2000.

[18] L. Dolenc, A. Besset, and M. Billiard, "Hypersomnia in association with dysthymia in comparison with idiopathic hypersomnia and normal controls," Pflugers Archiv, vol. 431, no. 6, pp. R303-R304, 1996.

[19] N. E. Rosenthal, D. A. Sack, J. C. Gillin et al., "Seasonal affective disorder: a description of the syndrome and preliminary findings with light therapy," Archives of General Psychiatry, vol. 41, no. 1, pp. 72-80, 1984.

[20] V. E. Palchikov, D. Y. Zolotarev, K. V. Danilenko, and A. A. Putilov, "Effects of the seasons and of bright light administered at different times of day on sleep EEG and mood in patients with seasonal affective disorder," Biological Rhythm Research, vol. 28, no. 2, pp. 166-184, 1997.

[21] M. Terman, "Copyrighted diagnosis, patented treatment," Bulletin of the Society for Light Treatment and Biological Rhythms, vol. 6, pp. 27-29, 1994.

[22] K. V. Danilenko and A. A. Putilov, “The importance of full summer remission as a criterion for the diagnosis of seasonal affective disorder," Psychopathology, vol. 29, no. 4, pp. 230-235, 1996.

[23] M. Hamilton, "Development of a rating scale for primary depressive illness," The British Journal of Social and Clinical Psychology, vol. 6, no. 4, pp. 278-296, 1967.

[24] J. B. W. Williams, M. J. Link, N. E. Rosenthal, and M. Terman, Structured Interview Guide for the Hamilton Depression Rating Scale: Seasonal Affective Disorder Version (SIGH-SAD), New York State Psychiatric Institute, New York, NY, USA, 1988.

[25] V. A. Doskin, L. S. Lavrentyeva, M. P. Miroshnikov, and V. B. Sharay, "Test for differential self-assessment of functional state," Psychology Questions, vol. 6, pp. 141-146, 1973 (Russian).

[26] A. Rechtschaffen and A. Kales, Eds., A Manual of Standardized Terminology, Techniques and Scoring System for Sleep Stages of Human Subjects, UCLA Brain Information Service/Brain Research Institute, Los Angeles, Calif, USA, 1968.

[27] C. Iber, S. Ancoli-Israel, A. L. Chesson, and S. F. Quan, The AASM Manual for the Scoring of Sleep and Associated Events: Rules, Terminology and Technical Specifications, American Association of Sleep Medicine, Westchester, Ill, USA, 2007.
[28] A. A. Putilov, K. V. Danilenko, G. S. Russkikh, and L. K. Duffy, "Phase typing of patients with seasonal affective disorder: a test for the phase shift hypothesis," Biological Rhythm Research, vol. 27, no. 4, pp. 431-451, 1996.

[29] A. A. Putilov, G. S. Russkikh, and K. V. Danilenko, "Phase of melatonin rhythm in winter depression," Advances in Experimental Medicine and Biology, vol. 460, pp. 441-458, 1999.

[30] A. A. Putilov, O. G. Donskaya, O. A. Jafarova, and K. V. Danilenko, "Waking EEG power density in hypersomnic winter depression," in Society for Light Treatment and Biological Rhythms, vol. 12, p. 24, 2000.

[31] K. V. Danilenko and A. A. Putilov, "Melatonin treatment of winter depression following total sleep deprivation: waking EEG and mood correlates," Neuropsychopharmacology, vol. 30, no. 7, pp. 1345-1352, 2005.

[32] T. Åkerstedt, J. Axelsson, M. Lekander, N. Orsini, and G. Kecklund, "The daily variation in sleepiness and its relation to the preceding sleep episode-a prospective study across 42 days of normal living," Journal of Sleep Research, vol. 22, no. 3, pp. 258-265, 2013. 


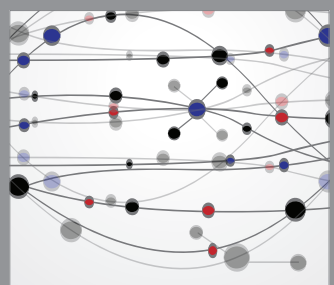

The Scientific World Journal
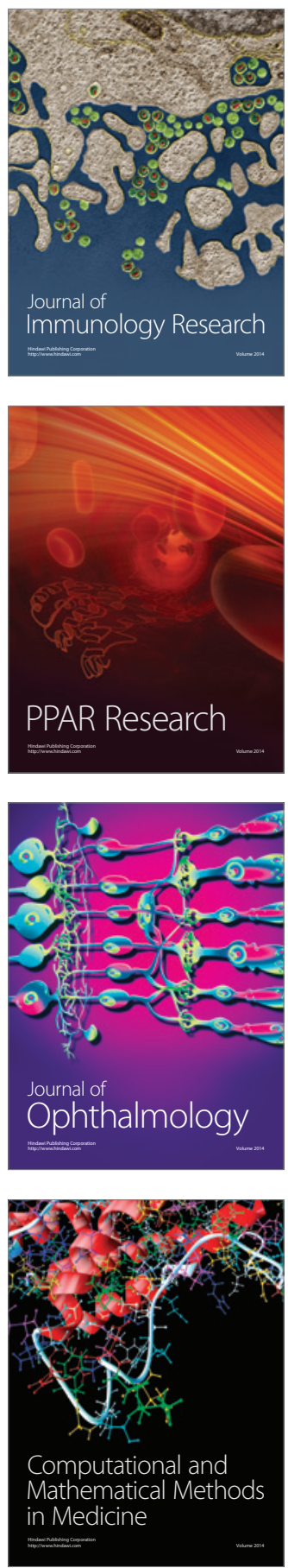

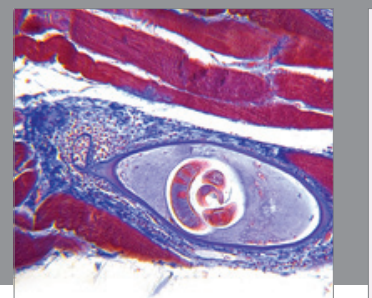

Gastroenterology

Research and Practice
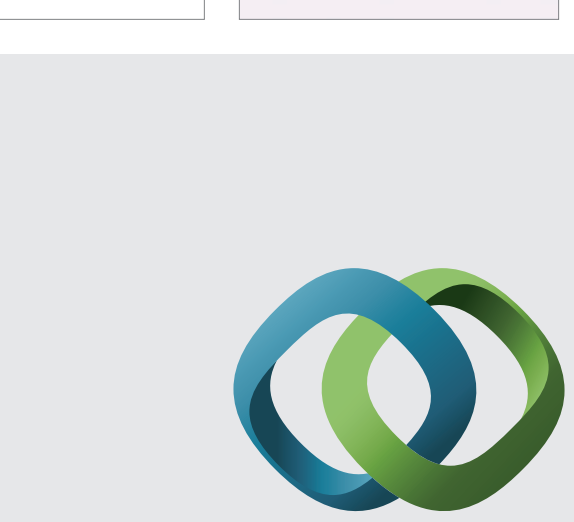

\section{Hindawi}

Submit your manuscripts at

http://www.hindawi.com
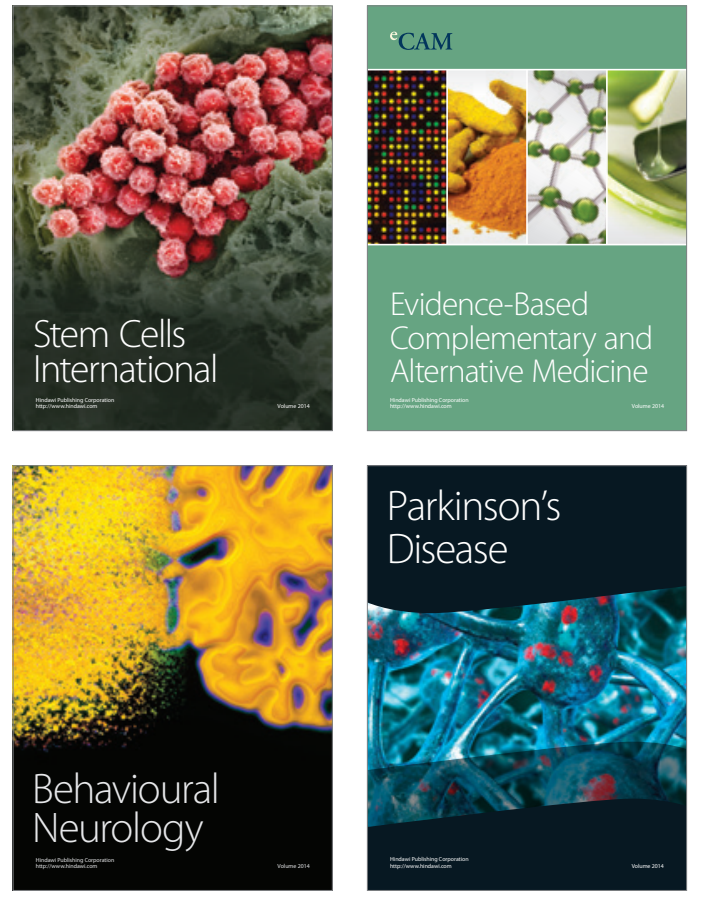
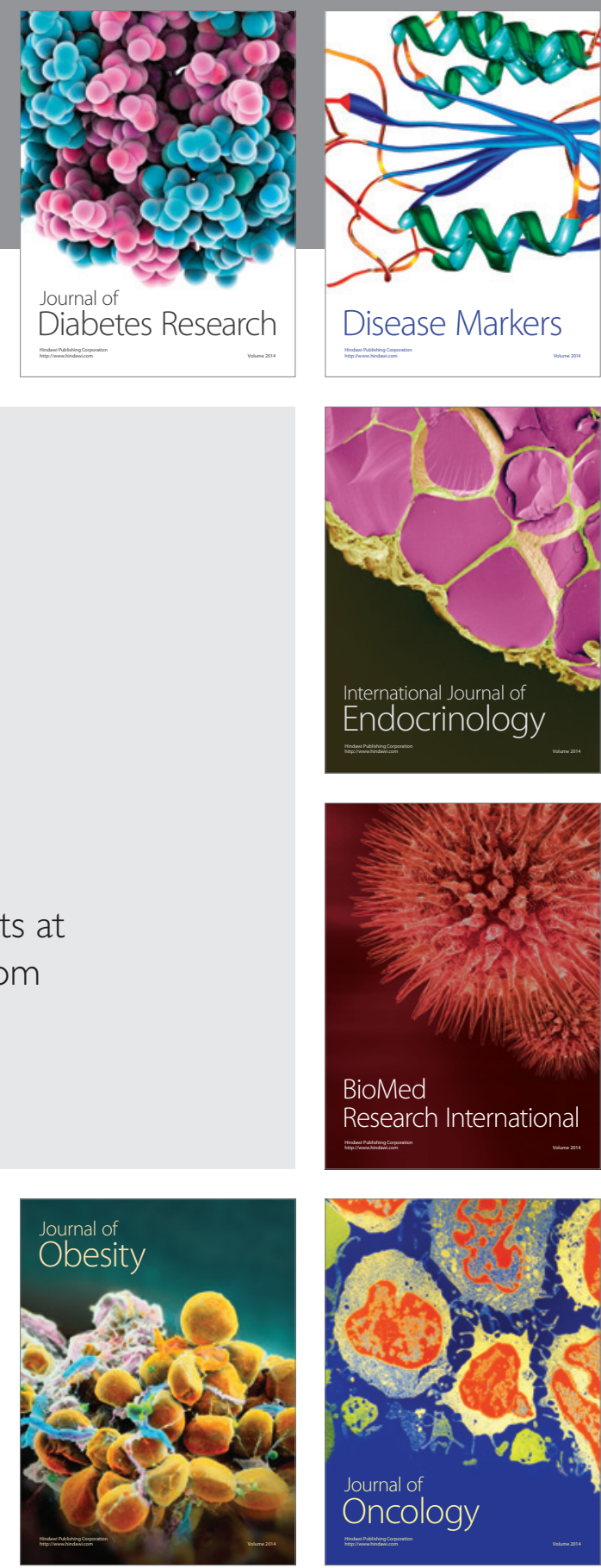

Disease Markers
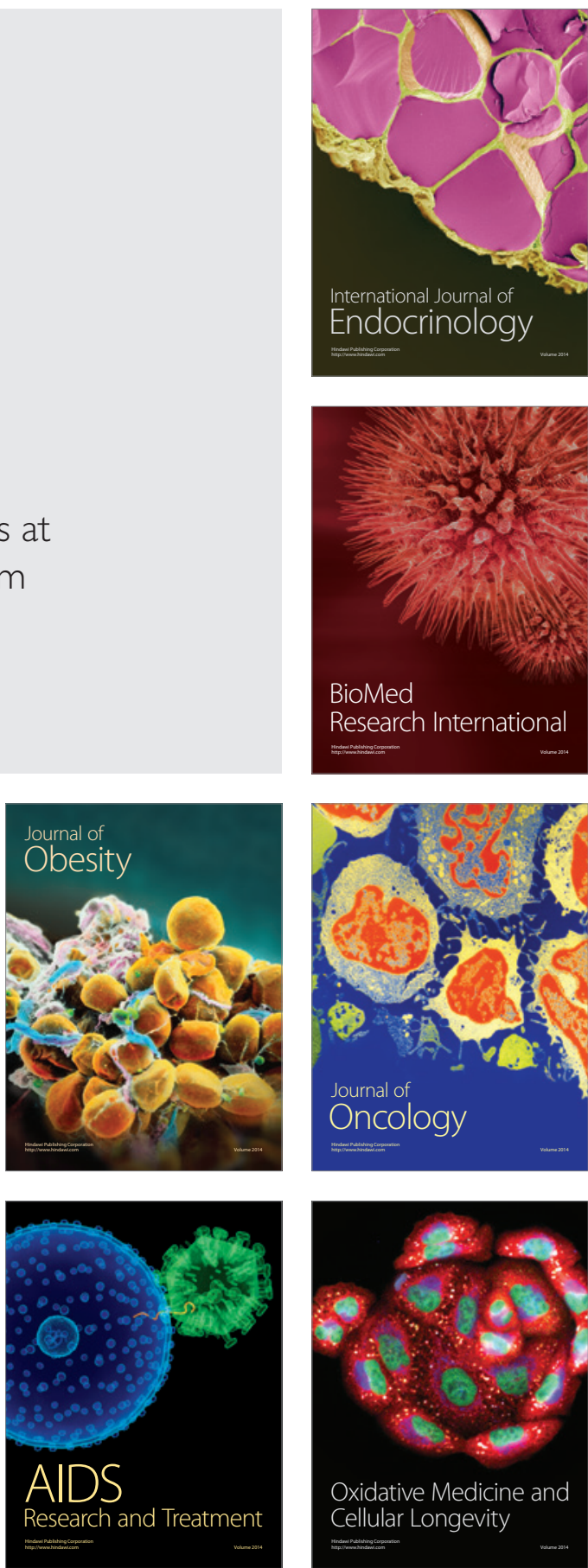